\title{
Complex Bilding Behavior of 2 ((4-Methyl-5-Nitro-6- (Pyrolidine-1-yl)Pyrimidine-2-yl)Amino)Propionic Acid in Aqueous Solution
}

\author{
S. A. A. Sajadi ${ }^{*}$, G. Bagherzadeh ${ }^{2}$, M. Kermane ${ }^{2}$, M. Khaleghian ${ }^{1}$ \\ ${ }^{1}$ Sharif University of Technology, Institute of Water \& Energy, Tehran, Iran \\ ${ }^{2}$ Departement of Chemistry, Birjand University, Birjand, Iran \\ Email: *sajadi@sharif.ac.ir
}

Received November 7, 2012; revised December 12, 2012; accepted December 19, 2012

\begin{abstract}
The acidity constants of MNPPAP ${ }^{1}$ were determined by potentiometric $\mathrm{pH}$ titration. The stability constants of the 1:1 complexes formed between $\mathrm{M}^{2+}: \mathrm{Ca}^{2+}, \mathrm{Mg}^{2+}, \mathrm{Mn}^{2+}, \mathrm{Co}^{2+}, \mathrm{Ni}^{2+}, \mathrm{Cu}^{2+}$ or $\mathrm{Zn}^{2+}$ and MNPPAP ${ }^{2-}$, were determined by potentiometric $\mathrm{pH}$ titration in aqueous solution $\left(I=0.1 \mathrm{M}, \mathrm{NaNO}_{3}, 25^{\circ} \mathrm{C}\right)$. The order of the stability constants was reported. It is shown that the stability of the binary M(MNPPAP) complexes is determined by the basicity of the carboxyl or amino group. All the stability constants reported in this work show the usual trend. The obtained order is $\mathrm{Ca}^{2+}<\mathrm{Mg}^{2+}>$ $\mathrm{Mn}^{2+}<\mathrm{Co}^{2+}<\mathrm{Ni}^{2+}<\mathrm{Cu}^{2+}>\mathrm{Zn}^{2+}$. The observed stability order for MNPPAP follows approximately the Irving-Williams sequence. It is shown that regarding to $\mathrm{M}$ ion-binding properties vital differences on complex bilding were considered. It is demonstrated, that in M-MNPPAP complexes, $\mathrm{M}$ ion is coordinated to the carboxyl group, $\mathrm{M}$ ion is also able to bild macrochelate over pyrimidine group. The up-mentioned results demonstrate that for M-MNPPAP complex the stability constants is also largely determined by the affinity of $\mathrm{M}^{2+}$ for carboxyl group. It is shown that MNPPAP can exert a direct influence on reaction mechanism through different kinds of metal ions and donor groups of MNPPAP.
\end{abstract}

Keywords: MNPPAP; Amino Acids; Divalent Metal Ions; Potentiometric Titration; Acidity; Stability Constants

\section{Introduction}

The $\alpha$-amino and $\alpha$-carboxyl groups of amino acids play a prominent role in metal ion binding. There are many examples of side chain functional groups that also interact with metal ions. Peptides interact with metal ions primarily through side chain functional groups, although there are many examples of peptide amide nitrogens functioning as donor atoms with certain metal ions. Many physiologically important peptides function as metal complexes [1,2]. In Figure 1, it is shown the chemical structure of MNPPAP.

MNPPAP, considered in this study, contains similar groups in its structure, which can show identical properties to amino acids [3]. Among the side chains of amino acids, the indole moiety is the most potent electron donor [4]. Indeed, charge-transfer-type interactions between tryptophan or other indole derivatives and nucleosides or nucleotides occur in aqueous solution [5-9]. Based on

\footnotetext{
"Corresponding author.

${ }^{1}$ MNPPAP: 2 ((4-methyl-5-nitro-6-(pyrrolidine-1-yl)pyrimidine-2-yl)amino propionic acid.
}

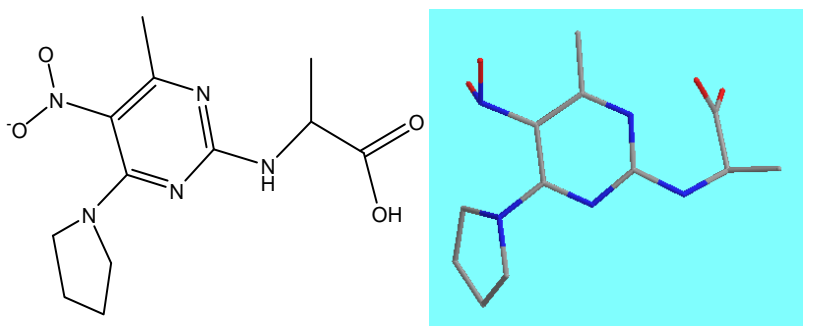

Figure 1. Chemical structure of MNPPAP.

above-mentioned essential role of amino acids is interesting to study the interaction between other metal ions with MNPPAP. Because of the essential rolls of aminoacids in biological systems is important to investigate their interactions with different metal ions and the regarding complex bilding. Due to the structural similarity of amino acids with MNPPAP, we can expect that some common behavior. For example, MNPPAP has a carboxyl group which can coordinate with metal ions. Unlike the primaries amine such as amino acids, in MNPPAP exists a secondary amine group. Secondary amine groups are normally inhibited groups for easy coordination. On 
the other hand, it is possible that a metal ion simultaneously coordinates to carboxyl group and binds to the $\mathrm{N}(3)$ pyrimidine ring, thus a macrochelate.

\section{Experimental}

\subsection{Materials}

The nitrate salt of $\mathrm{Na}^{+}, \mathrm{Ca}^{2+}, \mathrm{Mg}^{2+}, \mathrm{Mn}^{2+}, \mathrm{Co}^{2+}, \mathrm{Ni}^{2+}$, $\mathrm{Cu}^{2+}$, and $\mathrm{Zn}^{2+}$ (all pro analysis) were from Merck, Darmstadt, Germany. MNPPAP was synthesized by G. Bagherzadeh according to published procedures [10]. The purification was carried out carefully and was about $98 \%$. All the starting materials were of pro analysis grade and used without further purification. Potassium hydrogen phthalate and standard solutions of sodium hydroxide (titrasol), nitric acid, EDTA and of the buffer solutions of $\mathrm{pH}$ 4.0, 7.0 and 9.0 were all from Merck. All solutions were prepared with de-ionized water. Water was purified by Milil-Q water purification system, deionized and distillated.

\section{2. pH Titrations, Reagents}

Carbonate-free sodium hydroxide $0.03 \mathrm{M}$ was prepared and standardized against sodium hydrogen phthalate and a standard solution of nitric acid $0.5 \mathrm{mM}$. M (П) nitrate solution $(0.03 \mathrm{M})$ was prepared by dissolving the above substance in water and was standardized with standard solution of EDTA $0.1 \mathrm{M}$ (triplex).

\subsection{Apparatus}

All pH titrations were performed using a Metrohm 794 basic automatic titrator (Titrino), coupled with a thermostating bath Hero at $\left(25^{\circ} \mathrm{C} \pm 0.1^{\circ} \mathrm{C}\right)$ and a Metrohm combined glass electrode $(\mathrm{Ag} / \mathrm{AgCl})$. The $\mathrm{pH}$ meter was calibrated with Merck standard buffer solutions (4.0, 7.0 and 9.0).

\subsection{Procedure}

For the determination of acid dissociation constants of the ligand MNPPAP, an aqueous solution $(0.3 \mathrm{mM})$ of the protonated ligand was titrated with $0.03 \mathrm{M} \mathrm{NaOH}$ at $25^{\circ} \mathrm{C}$ under nitrogen atmosphere and ionic strength of 0.1 $\mathrm{M}, \mathrm{NaNO}_{3}$. For the determination of binary (a ligand and $\mathrm{M}^{2+}$ ) system, the ratios used were 1:1, M (П): MNPPAP, $0.3 \mathrm{mM}$. This solution was titrated with $0.03 \mathrm{M} \mathrm{NaOH}$ under the same conditions mentioned above. Each titration was repeated seven times in order to check the reproducibility of the data.

\subsection{Calculation}

The acid dissociation constants $K_{\mathrm{H}_{2} \text { (MNPPAP) }}^{\mathrm{H}}$ and $K_{\mathrm{H}(\mathrm{MNPPAP})}^{\mathrm{H}}$ for $\mathrm{H}_{2}$ (MNPPAP) were calculated by an algebraic method [11,12]. The equilibrium involved in the formation of 1:1 complex of MNPPAP and a divalent metal ion may be expressed as Equations (1) and (2).

\section{Results and Discussion}

The potentiometric $\mathrm{pH}$-titrations $\left(25^{\circ} \mathrm{C}, 0.1 \mathrm{M}, \mathrm{NaNO}_{3}\right)$ were carried out to obtain the acidity and stability constants which are summarized in Tables $\mathbf{1}$ and 2.

\subsection{Acidity Constants}

MNPPAP ion $\left(\mathrm{MNPPAP}^{-}\right), \operatorname{RNHCH}\left(\mathrm{CH}_{3}\right) \mathrm{CO}_{2}^{-}$, is a one-basic species, and thus it can accept one proton on the carboxyl side. On the other hand MNPPAP-releases another proton, for which the following de-protonation equilibriums are hold:

$$
\begin{gathered}
\mathrm{H}_{2}(\text { MNPPAP }) \rightleftharpoons \mathrm{H}^{+}+\mathrm{H}(\text { MNPPAP })^{-} \\
K_{\left.\mathrm{H}_{2} \text { (MNPPAP }\right)}^{\mathrm{H}}=\left[\mathrm{H}(\text { MNPPAP })^{-}\right]\left[\mathrm{H}^{+}\right] /\left[\mathrm{H}_{2}(\text { MNPPAP })^{\text {MN }}\right]
\end{gathered}
$$

$$
\begin{gathered}
\mathrm{H}(\mathrm{MNPPAP})^{-} \rightleftharpoons \mathrm{H}^{+}+\mathrm{MNPPAP}^{2-} \\
K_{\mathrm{H}(\mathrm{MNPPA})}^{\mathrm{H}}=\left[\mathrm{MNPPAP}^{2-}\right]\left[\mathrm{H}^{+}\right] /\left[\mathrm{H}\left(\mathrm{MNPPAP}^{-}\right]\right.
\end{gathered}
$$

The two protons in $\mathrm{H}_{2}$ (MNPPAP) are released from $\mathrm{RNHCH}\left(\mathrm{CH}_{3}\right) \mathrm{CO}_{2} \mathrm{H}$ according to equilibriums (1) and (2). It is also closed to the de-protonation of acetate groups which occurs at the terminal acetate groups of related amino acids [11,12]. MNPPAP can release the first proton from the terminal acetate group. Hence, here due addition to equilibrium (1) should be considered, which takes place near at $\mathrm{pH} \approx 3$ (Table 1 ).

\subsection{Stability of Binary and Ternary Complexes}

If we abbreviate for simplicity associating of $\mathrm{Ca}^{2+}, \mathrm{Mg}^{2+}$, $\mathrm{Mn}^{2+}, \mathrm{Co}^{2+}, \mathrm{Ni}^{2+}, \mathrm{Cu}^{2+}$, and $\mathrm{Zn}^{2+}$ with $\mathrm{M}^{2+}$, then one may write the following two equlibriums of (3) and (4):

$$
\begin{aligned}
& \mathrm{M}^{2+}+\mathrm{H}(\mathrm{MNPPAP})^{-} \mathrm{M}\left(\mathrm{H} ; \mathrm{MNPPAP}^{+}\right. \\
& K_{\mathrm{M}(\mathrm{H} ; \mathrm{MNPPAP})}^{\mathrm{M}} \\
& =\left[\mathrm{M}\left(\mathrm{H} ; \mathrm{MNPPAP}^{+}\right] /\left[\mathrm{M}^{2+}\right]\left[\mathrm{H}\left(\mathrm{MNPPAP}^{-}\right]\right.\right. \\
& \mathrm{M}^{2+}+(\mathrm{MNPPAP})^{2-} \mathrm{M}(\mathrm{MNPPAP}) \\
& K_{\mathrm{M}(\mathrm{MNPPAP})}^{\mathrm{M}}=[\mathrm{M}(\mathrm{MNPPAP})] /\left[\mathrm{M}^{2+}\right]\left[\mathrm{MNPPAP}^{2-}\right](4 \mathrm{H})
\end{aligned}
$$

The experimental data of the potentiometric $\mathrm{pH}$ titrations may be completed by considering the above-mentioned equilibria (1) through (4), if the evaluation thereof is not carried into the $\mathrm{pH}$ range, where hydroxo complex formation occurs. 
Table 1. Negative logarithm of the acidity constants of $\mathrm{H}_{2}(\mathrm{MNPPAP})$ at $25^{\circ} \mathrm{C}, 0.1 \mathrm{M}, \mathrm{NaNO}_{3}$, Equations (1) and (2).

\begin{tabular}{ccc}
\hline No. & Species & $\mathrm{pKa}^{*}$ \\
\hline 1 & $\mathrm{H}_{2}$ (MNPPAP) & $2.92 \pm 0.04$ \\
2 & $\mathrm{H}($ MNPPAP) & $5.15 \pm 0.02$ \\
\hline
\end{tabular}

*The given errors are three times the standard error of the mean value or the sum of the probable systematic errors.

Table 2. Logarithm of the stability constants of binary complexes of $\mathrm{M}^{2+}$ at $25^{\circ} \mathrm{C}, \mathrm{O.1} \mathrm{M}, \mathrm{NaNO}_{3}{ }^{*}$, Equation (4).

\begin{tabular}{ccc}
\hline No. & Species & $\log K_{\mathrm{M}(\mathrm{Trp})}^{\mathrm{M}}$ \\
\hline 1 & $\mathrm{Ca}^{2+}$ & $1.87 \pm 0.08$ \\
2 & $\mathrm{Mg}^{2+}$ & $3.50 \pm 0.08$ \\
3 & $\mathrm{Mn}^{2+}$ & $3.12 \pm 0.05$ \\
4 & $\mathrm{Co}^{2+}$ & $3.31 \pm 0.07$ \\
5 & $\mathrm{Ni}^{2+}$ & $3.48 \pm 0.06$ \\
6 & $\mathrm{Cu}^{2+}$ & $4.05 \pm 0.05$ \\
7 & $\mathrm{Zn}^{2+}$ & $3.64 \pm 0.08$ \\
\hline
\end{tabular}

${ }^{*}$ The given errors are three times the standard error of the mean value or the sum of the probable systematic errors.

\subsection{Potentiometric Analyses}

The results of all potentiometric $\mathrm{pH}$-titration, i.e. acidity and stability constants, are summarized in Tables $\mathbf{1}$ and $\mathbf{2 .}$ The de-protonated MNPPAP ${ }^{2-}$ can accept two protons, to give the acid $\mathrm{H}_{2}$ (MNPPAP). The first one of these two protons of carboxylate residue is released; its $\mathrm{pKa}$ is $\approx 3$. However, $\mathrm{MNPPAP}^{-}$can release one more proton, which is $\mathrm{pH} \approx 5.2$. The measured first acidity constants in this work show good agreement with the same value received by other authors for related amino acids $[11,13,14]$. However, the carboxyl group is a far stronger acid than residue group [15].

The stability constants of the binary complexes of $\mathrm{M}$ (MNPPAP) were refined separately using the titration data of this system in a 1:1, ligand: $\mathrm{M}^{2+}$ ratio in the same conditions of temperature and ionic strength (according Equations (3) and (4)), as they were not in agreement with reported value for related amino acids $[11,14]$. We didn't receive reasonable results for $K_{\mathrm{M}(\mathrm{H}: \mathrm{MNPPAP})}^{\mathrm{M}}$. All the stability constants of Table 2 show approximately the usual trend. The obtained order is $\mathrm{Ca}^{2+}<\mathrm{Mg}^{2+}>\mathrm{Mn}^{2+}<$ $\mathrm{Co}^{2+}<\mathrm{Ni}^{2+}<\mathrm{Cu}^{2+}>\mathrm{Zn}^{2+}$. The observed stability order for MNPPAP follows approximately the Irving-Williams sequence (except $\mathrm{Mg}^{2+}$ ) [16] (Figure 2). Based on the HSAB Principle: Hard acids prefer to coordinate to hard bases, and soft acids prefer to coordinate soft bases. This means that metal ions like $\mathrm{Mg}^{2+}, \mathrm{Mn}^{2+}$ prefer to coordinate on carboxyl site and the other above-mentioned

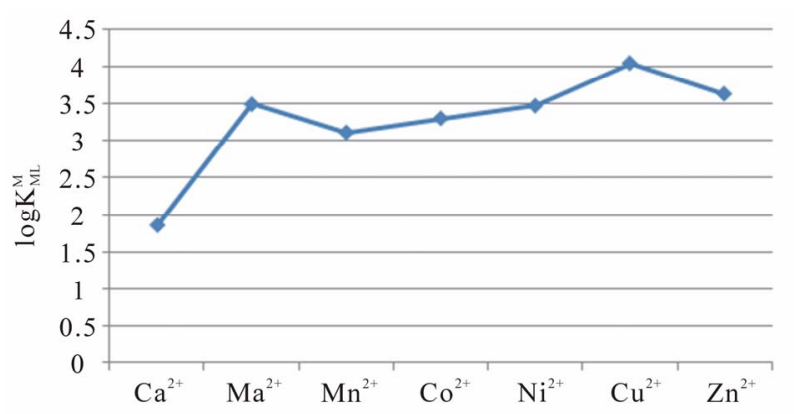

Figure 2. Irving-Williams sequence-type plot for the 1:1 complexes of $\mathrm{Ca}^{2+}$ to $\mathrm{Zn}^{2+}$ with MNPPAP (see Table 2).

metal ions (Table 2) (as borderline metal ions) show tendency for both carboxyl group and for pyrimidine group and can be coordinate bidentate [17].

Another interesting point is the tentative and simplified structure for the macrochelated outer-sphere isomer. In the case of hard-metals such as $\mathrm{Mg}^{2+}$, and $\mathrm{Mn}^{2+}$ can be observed the outer-sphere complex bilding. It should be noted that the term outer-sphere is used here with regard to the $\mathrm{M}^{2+} \mathrm{N}(3)$-pyrimidine ring coordination. If an intramolecular direct $\mathrm{M}^{2+} / \mathrm{N}(3)$-pyrimidine ring coordination occurs, then it is strictly more favorable to have a water molecule between $\mathrm{M}^{2+}$ and $\mathrm{N}(3)$-pyrimidine ring. With an outer-sphere N(3)-pyrimidine ring binding can increase the stability of binary complexes.

Now we are able to compare the stability constants of two species M (Am) and M (MNPPAP) (see Table 3). Am represents the amino acids such as Leucine, Valine, Alanine, Glycine, and Methionine. It could easily distinguish that these constants of M (MNPPAP) are not (within the propabable systematic errors) the same of the corresponding $\mathrm{M}(\mathrm{Am})$ species. These mean that we can not distinguish a reasonable increased stability in case of $\mathrm{M}$ (MNPPAP).

This is an interesting point, because interaction of hard metals such as $\mathrm{Mg}^{2+}$ with MNPPAP is considerable, which we can use from results (Table 2).

Based on the results of this work we can draw the conclusion, that hard metal ions just with different stability constants could not have similarly interaction with MNPPAP. The metal ions such as $\mathrm{Co}^{2+}, \mathrm{Ni}^{2+}, \mathrm{Cu}^{2+}$ and $\mathrm{Zn}^{2+}$ are able to have additional interactions with MNPPAP (Figure 3).

Amino acids contain a primary amine group, but in MNPPAP there is a secondary amine. As we see from the results, there is a large difference between the second acidity constants of amino acids and MNPPAP. This means a difference of about four log units (Table 1). We also see big differences between stability constants of amino acids and MNPPAP. In previous work it has shown that amino acids bind simultaneously bi-dentate to metal ions (on carboxyl- and amine-group), which then 
Table 3. Logarithm of the stability constants of binary complexes of $\mathrm{M}^{2+}$ with $\mathrm{L}$ at $25^{\circ} \mathrm{C}, 0.1 \mathrm{M}, \mathrm{NaNO}_{3}{ }^{*}$, Equation (4). L: Trp (tryptophan), and related compounds such as Met (methionine), Ala (Alanine), Leu (Leucine), Val (Valine), Gly (Glycine), and MNPPAP.

\begin{tabular}{cccccc}
\hline \multirow{2}{*}{ No. } & Ligand & \multicolumn{5}{c}{$\log K_{\mathrm{M}(\mathrm{L})}^{\mathrm{M}}$} \\
\cline { 3 - 6 } & & $\mathrm{Mn}^{2+}$ & $\mathrm{Co}^{2+}$ & $\mathrm{Cu}^{2+}$ & $\mathrm{Zn}^{2+}$ \\
\hline 1 & Trypyophan $^{\mathrm{a}}$ & $3.34 \pm 0.05$ & $4.34 \pm 0.07$ & $8.05 \pm 0.05$ & $5.00 \pm 0.08$ \\
2 & Methionine $^{\mathrm{b}}$ & $3.59 \pm 0.05$ & $3.85 \pm 0.08$ & $7.96 \pm 0.02$ & $4.46 \pm 0.06$ \\
3 & Alanine $^{\mathrm{c}}$ & 3.24 & 4.82 & 8.18 & 5.16 \\
4 & Leucine $^{\mathrm{c}}$ & 2.15 & 4.49 & 7.00 & 4.92 \\
5 & Valine $^{\mathrm{c}}$ & 2.84 & - & 7.92 & 5.00 \\
6 & Glycine $^{\mathrm{c}}$ & 3.20 & 5.23 & 8.22 & 5.16 \\
7 & MNPPAP $^{2}$ & $3.12 \pm 0.05$ & $3.31 \pm 0.07$ & $4.05 \pm 0.05$ & $3.64 \pm 0.08$ \\
\hline
\end{tabular}

a) From $[11,12]$; b) From [12]; c) From [11]. ${ }^{*}$ The given errors are three times the standard error of the mean value or the sum of the probable systematic errors.

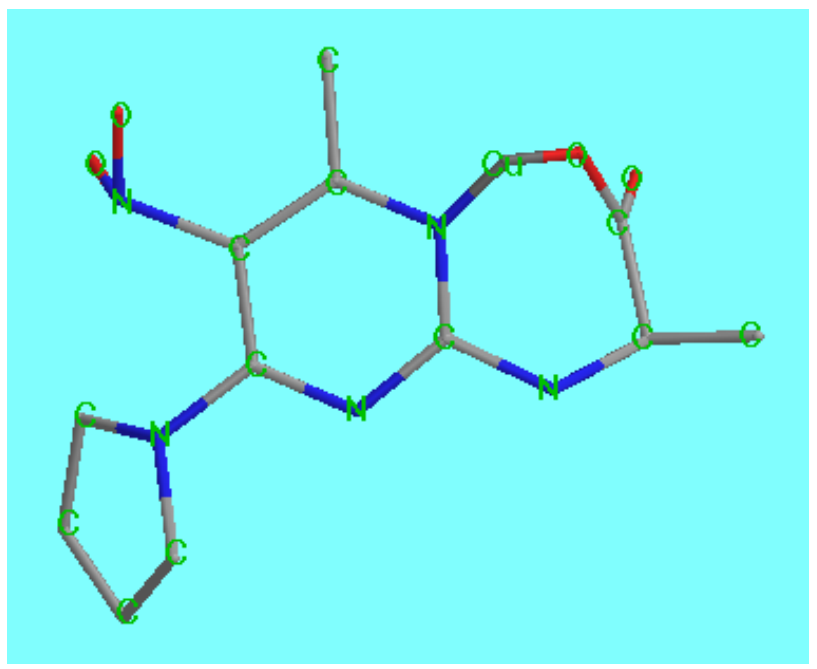

Figure 3. Schematic structures of the species with interactions according to equilibrium (4) for $\mathrm{Cu}($ MNPPAP). The structure was drawn with the program CS Chem 3D, version 3.5, from Cambridge Software Corporation.

leads to a larger stability. But in the case of MNPPAP, metal ions coordinate on carboxyl-group and $\mathrm{N}(3)$ form of prymidine ring. This shows a smaller stability.

\section{REFERENCES}

[1] B. Widner, B. Wirleitner, G. Baier-Bitterlich, et al., Ar- chivum Immunologiae et Therapiae Experimentalis, Vol. 4, 2000, pp. 251-258.

[2] J. L. Celenza, Current Opinion in Plant Biology, Vol. 3, 2001, pp. 34-40.

[3] IUPAC-IUBMB Joint Commission on Biochemical Nomenclature, "Nomenclature and Symbolism for Amino Acids and Peptides," Recommendations on Organic \& Biochemical Nomenclature, Symbols \& Terminology etc., 2007.

[4] R. Foster, "Charge Transfer Complexes," Academic Press, Amsterdam, 1969.

[5] F. Morita, "Molecular Complex of Tryptophan with ATP or Its Analogs," Biochimica et Biophysica Acta (BBA)General Subjects, Vol. 343, No. 3, 1974, pp. 674-681. doi:10.1016/0304-4165(74)90288-8

[6] D. L. Nelson and M. M. Cox, "Lehninger, Principles of Biochemistry," 3rd Edition, Worth Publishing, New York, 2000.

[7] L. Stryer, "Biochemistry," 4th Edition, W.H. Freeman and Company, New York, 1995.

[8] http://www.anyvitamins.com/millenium2000.htm

[9] http://www.evitamins.com/healthnotes.asp?ContentID $=10$ 25008

[10] M. Bakavoli, G. Bagherzadeh and M. Rahimizadeh, "Synthesis of Optically Active Imidazo[1,2-a]Pyrimidin-3(2H)Ones," Mendeleev Communications, Vol. 15, No. 4, 2005, pp. 145-146. doi:10.1070/MC2005v015n04ABEH001994

[11] A. E. Martel, Critical Stability Constants of Metal Complexes, Vol. 26, 2006.

[12] S. A. A. Sajadi, A. A. Alamolhoda and A. Nazari Alavi, Scientica Iranica, 2012.

[13] "Handbook of Chemistry \& Physics," Vol. 55, 1975.

[14] L. D. Pettit and H. K. J. Powel, "IUPAC Stability Conatants Database, Release 3, Version 3.02," Academic Software Timble, 1998.

[15] H. Sigel, A. D. Zuberbuehler and O. Yamauchi, "Comments on Potentiometric $\mathrm{pH}$ Titrations and the Relationship between $\mathrm{pH}-$ Meter Reading and Hydrogen Ion Concentration," Analytica Chimica Acta, Vol. 255, No. 1, 1991, pp. 63-72. doi:10.1016/0003-2670(91)85088-A

[16] H. Irving and R. J. P. Williams, "The Stability of Transition-Metal Complexes," Journal of the Chemical Society, 1953, pp. 3192-3210. doi:10.1039/jr9530003192

[17] H. Sigel and C. F. Naumann, Journal of the Chemical Society, Vol. 98, No. 3, 1976, pp. 730-739. 